\title{
COOPERAÇÃO E COLABORAÇÃO FEDERATIVAS NA EDUCAÇÃO PROFISSIONAL E TECNOLÓGICA
}

\author{
LuCilia REgina DE SouZa Machado* \\ MARIA JANETE VELTEN ${ }^{* *}$
}

\begin{abstract}
RESUMO: A Constituição Federal de 1988 prevê, no parágrafo único do artigo 23, a regulamentação do regime de cooperação entre a União, os estados, o Distrito Federal e os municípios por leis complementares. Porém, isso ainda não aconteceu e formas de colaboração federativa para a oferta de educação profissional e tecnológica se intensificaram a partir de 2003. Baseado em pesquisa bibliográfica e documental, este artigo analisa a questão, em especial alguns aspectos sobre a importância, avanços e limitações desse processo colaborativo em face da necessidade e dos desafios da integração sistêmica dessa modalidade educacional na edificação do Sistema Nacional de Educação e da regulamentação do regime de cooperação institucional.
\end{abstract}

Palavras-chave: Federalismo e educação. Regimes de colaboração e cooperação. Educação profissional e tecnológica.

\section{FEDERATIVE COOPERATION AND COLLABORATION IN PROFESSIONAL AND TECHNOLOGICAL EDUCATION}

ABSTRACT: The 1988 Constitution - article 23, single paragraph -, provides for the regulation of the cooperation between Union, States, Federal District and the municipalities by supplementary laws. However, this has not happened yet and federative forms of collaboration, in order to offer professional and technological education have been intensified since 2003. Based on relevant literature and documents, this article examines this question, especially some aspects related to the importance, advances and limitations of the collaborative process in light of the requirement and challenges of the systemic integration of this kind of education in the building of the National Education System and the regulation of the institutional cooperation framework.

Key words: Federalism and education. Frameworks for collaboration and cooperation. Professional and Technological education.

\footnotetext{
* $\quad$ Centro Universitário UNA. Belo Horizonte (MG) - Brasil.

** Centro Federal de Educação Tecnológica (Cefet) de Minas Gerais. Nepomuceno (MG) - Brasil.

Contato com as autoras: <lsmachado@uai.com.br>
} 


\title{
CoOpÉrATION ET COLLABORATION FÉdÉRATIVES DANS L'ÉDUCATION PROFESSIONNELLE ET TECHNOLOGIQUE
}

\begin{abstract}
RÉSUMÉ: La Constitution Fédérale de 1988 prévoit, dans le paragraphe unique de l'article 23, la réglementation du régime de coopération entre l'Union, les États, le District Fédéral et les Villes par des lois complémentaires. Néanmoins, cela n'est pas encore arrivé et des formes de collaboration fédérative pour l'offre d'éducation professionnelle et technologique se sont intensifiées à partir de 2003. Basé sur une recherche bibliographique et documentaire, cet article analyse la question, surtout quelques aspects sur l'importance, progrès et limitations de cette procédure colaborative en raison de la nécessité et des défis de l'intégration systémique de cette modalité éducationnelle dans la construction du Système National d'Éducation et de la réglementation du régime de coopération institutionnelle.
\end{abstract}

Mots-clés: Fédéralisme et éducation. Régimes de collaboration et coopération. Éducation Professionnelle et Technologique.

\section{Introdução}

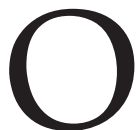

tema principal ("O PNE na articulação do Sistema Nacional de Educação: participação popular; cooperação federativa e regime de colaboração") da II Conferência Nacional de Educação (Conae), programada para ocorrer em fevereiro de 2014, motivou a elaboração deste artigo. Ela tem por objetivo geral "propor política nacional de educação, indicando responsabilidades, corresponsabilidades, atribuições concorrentes, complementares e colaborativas entre os entes federados e os sistemas de ensino" (FÓRUM NACIONAL DE EDUCAÇÃO, 2012, p. 3). Este artigo busca se inserir nesse debate a partir da contextualização e de questões suscitadas pela colaboração e cooperação federativas no campo da educação profissional e tecnológica. Uma delas guarda grande intimidade com um dos objetivos específicos da II Conae:

e) Integrar todos os níveis, etapas e modalidades da educação numa abordagem sistêmica, com vistas a edificar o Sistema Nacional de Educação, especialmente no tocante ao planejamento e gestão, avaliação, financiamento, formação inicial e continuada dos trabalhadores em educação, além da garantia das condições de oferta de ensino com qualidade social. (Idem, ibid., p. 4)

A educação profissional no Brasil traz um histórico de dualidade estrutural na sua organização e oferta, o que tem contribuído para a sua marginalização na atenção que deveria receber de todas as redes de ensino, especialmente das estaduais, do Distrito Federal e municipais. Fundamentada na Emenda Constitucional n. 14/96, Lei n. 9.394/96, Lei n. 9.424/96, Decreto n. 2.208/97, Portaria MEC n. 646/97 e Portaria MEC n. 1.005/97, a reforma da educação profissional e tecnológica do Governo Fernando 
Henrique Cardoso se assentou nessa lógica dualista e em ideais gerencialistas de cunho neoliberal. Concebida como oferta paralela à educação geral, a educação profissional e tecnológica acabou ficando à mercê de uma atenção aligeirada, que compromete sua estruturação, desenvolvimento e qualidade nas redes de ensino e, consequentemente, o cumprimento de direitos sociais. Esses dispositivos legais reforçaram o que o Governo Itamar Franco havia instituído com a Lei n. 8.948/94, um separado Sistema Nacional de Educação Tecnológica, concepção que sofreu revés com a promulgação da Lei n. 11.195/05.

Os efeitos desses dispositivos legais não foram desprezíveis sobre as redes estaduais de ensino. Ao ordenar que a oferta da educação profissional fosse divorciada da educação geral, o Decreto n. 2.208/97 provocou o desaparelhamento e até o fechamento de muitas escolas e cursos técnicos públicos. Estimulou igualmente o surgimento de diferentes modelos de gestão estadual da educação profissional, processo reforçado por concepções de reforma gerencialista do Estado. Em 2005, um grupo de gestores estaduais se uniu para constituir o Fórum Nacional de Gestores Estaduais de Educação Profissional, visando à unidade federativa nesse nível da Federação e a busca de condições adequadas para o desenvolvimento dessa modalidade educacional. Batistolli, Grossi Jr. e Garcia (2010) relatam que eventos da Secretaria de Educação Profissional e Tecnológica (Setec) deram oportunidade para a formação desse fórum e que essa Secretaria o reconheceu também como espaço de articulação dos estados com a União, disponibilizando-lhe recursos. Em julho de 2011, esse Fórum passou a ser uma instância do Conselho Nacional dos Secretários de Educação (Consed) e se mantém como espaço de produção de informações sobre as redes públicas estaduais e do Distrito Federal e de articulação entre os gestores estaduais, e desses com o governo federal.

A revogação do Decreto n. 2.208/97 e as alterações na Lei n. 9.394/96 pela Lei n. 11.741/08, para a institucionalização da integração da educação profissional à educação básica e educação de jovens e adultos, representam alterações institucionais importantes, mas que não levaram a revisões críticas de modelos de gestão estadual da educação profissional e tecnológica. Pesquisa realizada em 2010 pelo Departamento Intersindical de Estatística e Estudos Socioeconômicos (Dieese) mostrou que:

Dentre os 22 estados, incluindo o Distrito Federal, que participaram do levantamento, 14 informaram que a Educação Profissional está vinculada à secretaria de educação. Dos demais restantes, em cinco eram vinculados à Ciência e Tecnologia e em quatro vinculados a ambas. Este resultado evidencia certa divisão de papéis entre as secretarias da Educação e as da Ciência e Tecnologia no que tange à Educação Profissional. No caso dos estados que possuem dupla vinculação, cabe às secretarias de Educação a gestão da oferta de Educação Profissional integrada ao ensino médio e às secretarias de Ciência e Tecnologia, a gestão das ofertas concomitante e subsequente ao ensino médio. (DIEESE, 2012, p. 31) 
Outra questão para a qual o estudo do Dieese aponta diz respeito à forma como a educação profissional se vincula à estrutura administrativa do Estado. Quanto a isso, viu-se que:

Das 22 unidades investigadas, em quatro a gestão da Educação Profissional é realizada por intermédio de órgãos da administração indireta. Isso ocorre nos estados do Acre, Amazonas, Rio de Janeiro e São Paulo. Estes órgãos podem ser centros, institutos ou até mesmo fundações, mas, de acordo com a personalidade jurídica, são estruturas autárquicas. Em Pernambuco e no Ceará existem duas organizações sociais - que não fazem parte da estrutura administrativa destas unidades - com as quais esses estados firmam contratos de gestão pelos quais transferem a elas uma parte da execução dos serviços de Educação Profissional. Vale ressaltar que, nestes estados, a maior parte da oferta de Educação Profissional está a cargo das respectivas secretarias de Educação. (Idem, ibid., p. 32)

Este artigo aborda, assim, e a partir de pesquisa bibliográfica e documental, formas de cooperação e colaboração federativa na educação profissional e tecnológica brasileira. Tem em vista demarcar elementos que configurem a importância, avanços e limitações desse processo colaborativo, em face dos desafios da integração sistêmica dessa modalidade educacional na edificação do Sistema Nacional de Educação e da necessidade de construção do regime de cooperação institucional.

Entre os segmentos que participarão da Conae, a educação profissional estará representada por 500 delegados/as eleitos/as nos estados, 20\% de um total de 2.500 . Serão 74 gestores estaduais e municipais da educação profissional, 43 gestores de estabelecimentos federais da educação profissional, 89 gestores da educação profissional privada, 89 trabalhadores da educação profissional privada, 89 trabalhadores da educação profissional pública, 43 conselheiros estaduais de educação profissional e 73 estudantes. (FÓRUM NACIONAL DE EDUCAÇÃO, 2012, p. 21)

A finalidade, portanto, deste texto é de contribuir para o debate sobre o tema principal da II Conae, considerando que é preciso novas institucionalidades na relação entre entes federados.

\section{Aspectos conceituais e legais da relação federativa: implicações para a educação profissional e tecnológica}

O regime de colaboração federativa na educação está previsto na Constituição Federal brasileira no seu artigo 211 e no Título IV da lei que estabelece as diretrizes e bases da educação nacional (LDB, Lei n. 9.394/96), que em seu artigo 8o o reitera, determinando à União, estados, Distrito Federal e municípios a organização, sob tal espírito, dos seus respectivos sistemas de ensino. As formas de realizar essa colaboração foram elencadas por essa LDB sem menção explícita à educação profissional e tecnológica. 
Pesquisa realizada junto a 29 municípios do estado do Rio de Janeiro sobre cobertura municipal da educação profissional pela via do regime de colaboração (SOUZA; RAMOS; DELUIZ, 2007), entre 2002 e 2005, concluiu que a produção científica neste campo se mostrava incipiente, observação que permanece válida. Concluiu também que a colaboração federativa nessa modalidade educacional se mostrava muito tímida. Os autores inferiram que esses dois problemas contribuíam para dificultar "[...] a compreensão, entre outros aspectos, da identidade da educação profissional no âmbito dos sistemas educacionais, particularmente municipal, de modo a verificar a pertinência de se considerá-la, formalmente, como objeto de ação cooperada entre os entes federados" (p. 20). Constataram, no contexto estudado, que tal lacuna no compartilhamento de responsabilidades previsto pela LDB era preenchida por medidas em benefício do setor privado, especialmente do Sistema S.

O parágrafo único do artigo 23 da Constituição Federal anunciou que normas para a regulamentação da cooperação entre a União e os estados, o Distrito Federal e os municípios seriam objeto de leis complementares. Porém, 25 anos passados, isso ainda não aconteceu. A transferência de receitas intergovernamentais por meio de fundo de participação (pela via do Fundo de Manutenção e Desenvolvimento da Educação Básica e de Valorização dos Profissionais da Educação, por exemplo) tem sido reconhecida como um mecanismo de cooperação.

Efetivamente, o que tem prevalecido nas relações entre entes federados, visando à superação de desequilíbrios regionais e sociais em matéria de educação, são convênios pontuais, temporários e por adesão, que dependem, portanto, de relações de confiança, vontades e consensos políticos para fins de estabelecimento de parcerias. Logo, o regime de colaboração federativa acaba se definindo por ações de governos e não por políticas de Estado. Trata-se de um mecanismo que termina por reforçar a tradição patrimonialista dos poderes públicos no Brasil, os casuísmos, a perspectiva da descontinuidade das políticas públicas e a relativização de direitos sociais.

A Constituição Federal determinou a regulamentação do regime de cooperação, mas a Emenda Constitucional n. 14/1996 levou à consagração do regime de colaboração na educação brasileira, o que foi regulamentado pela LDB logo a seguir. Além disso, o fundo contábil que essa Emenda anunciou se restringia apenas à manutenção e desenvolvimento do ensino fundamental e de valorização do seu magistério (o antigo Fundef), cindindo a educação básica, o que, para a educação profissional e tecnológica, significou o reforço do desamparo ao qual sempre esteve relegada. No final de 2006, essa orientação sofreu um revés importante com a aprovação da Emenda Constitucional n. 53, que trouxe perspectivas para avanços no regime de cooperação, incluindo a criação do Fundo de Manutenção e Desenvolvimento da Educação Básica e de Valorização dos Profissionais da Educação (Fundeb), contemplando assim a educação infantil, o ensino médio e a educação de jovens e 
adultos. Em 2009, a Emenda Constitucional n. 59 alargou a faixa etária da escolarização obrigatória, passando a ser de 4 a 17 anos, ampliando o direito subjetivo à educação.

O tema principal da II Conae repõe o debate do federalismo na educação brasileira à luz dos dias atuais. No campo específico da educação profissional e tecnológica, mudanças no contexto econômico, tecnológico, social e cultural e demográfico têm feito aumentar demandas sociais por acesso e qualidade, inclusive por públicos que tradicionalmente não se interessavam por essa modalidade educacional. Nos últimos anos, esse cenário foi alterado também por conta do sensível aumento dos investimentos financeiros e outras formas de estímulo do governo federal às ações dos entes subnacionais nessa esfera educacional. Estes vêm acompanhados de incentivos à superação dos tradicionais e questionáveis divórcios entre educação geral e profissional, formação política e técnica, cultura e trabalho, humanismo e ciência. A educação profissional e tecnológica tem sido reclamada por segmentos importantes da sociedade brasileira como uma política pública nacional, de Estado, estratégica e de sustentabilidade ao desenvolvimento do país. Tudo isso pede mais do que formas de colaboração federativa, reclama por firmeza e efetividade dos papéis do Estado, nos seus diferentes níveis, e das instituições educacionais nessa expansão e mudança conceitual. Pede aos entes federados e às suas escolas a ampliação da cobertura, a articulação da educação profissional com a educação básica, a superação de práticas e conteúdos pedagógicos fragmentados, ofertas educativas apoiadas na informação, nos conhecimentos científicos e nas inovações tecnológicas; pede a articulação da formação inicial com os processos de educação continuada.

Os entes federados, na articulação e interlocução com os diversos setores da sociedade, são chamados à revisão das suas correntes formas de ação pública no campo da educação profissional e tecnológica. O compromisso com a redução das desigualdades sociais e regionais lhes solicita maior efetividade nas relações federativas de divisão de responsabilidades e de cooperação institucional.

Para potencializar os esforços existentes, expandir a oferta de vagas, qualificar as redes de ensino e otimizar as estruturas e recursos públicos no campo da educação profissional, a articulação das ações governamentais passa por diferentes formatos e arranjos, pois, além da convergência entre os entes federados, há aquelas que requerem o compromisso e envolvimento de diferentes ministérios federais, colocando a educação profissional e tecnológica em diálogo com o conjunto das políticas públicas.

As articulações entre níveis da Federação nesse campo educacional não têm sido, entretanto, homogêneas em razão de diferentes fatores. Concorrem aqueles de ordem histórica, política, ideológica e também os que não dependem propriamente da 
vontade, mas das condições e capacidades estrutural, financeira e técnica de atender tal convocação. O fato é que, por conta da inexistência de um substrato, de um Sistema Nacional de Educação, acabam ocorrendo muita fragmentação, pulverização, desarticulação, concorrência e sobreposição das ações, incluindo as de financiamento. A estratégia de efetivar políticas públicas, por meio de programas e projetos específicos, corre o risco de produzir tais consequências.

A questão do financiamento da educação profissional e tecnológica é emblemática do problema. Não há na legislação do Estado brasileiro a responsabilidade constitucional ou legal por esse financiamento. Assim, essa modalidade educacional não dispõe de definições sobre recursos próprios e/ou sobre quais são os montantes necessários para o seu desenvolvimento.

O tema da II Conae mostra-se, portanto, muito oportuno, pois a indicação de responsabilidades, corresponsabilidades, atribuições concorrentes, complementares e colaborativas entre os entes federados e os sistemas de ensino são fundamentais à consolidação da política nacional de educação profissional e tecnológica e de um Sistema Nacional de Educação realmente integrado.

\section{Cooperação federativa na educação profissional e tecnológica brasileira}

A cooperação federativa se define pela institucionalização de atribuições e de regras e procedimentos de relações intergovernamentais, que requerem ações de coordenação. No Brasil, a União representa o nível ou instância da Federação que realiza o papel de representar, articular e administrar o que há de comum entre os demais entes federativos e tem, diferentemente destes, poder soberano.

\footnotetext{
No âmbito dos estados preserva-se um grau específico de autonomia que lhes permite baixar normas próprias, mas sem a plenitude de que goza a União, uma vez que devem subordinar-se às diretrizes gerais traçadas pela União, esfera que escapa à sua atribuição. E quando passamos ao nível municipal, a autonomia torna-se bem mais restrita porque, no caso da educação, sequer a Constituição lhes faculta estabelecer normas próprias, o que é admitido apenas em caráter complementar pela LDB. (SAVIANI, 2011, p. 4)
}

O autor argumenta que a diferença de graus de autonomia não significa redução de importância das instâncias estaduais e municipais, já que

[...] é preciso também ter presente que a melhor forma de fortalecer as instâncias locais não é, necessariamente, conferir-lhes autonomia deixando-as, de certo modo, à própria sorte. Na verdade, a melhor maneira de respeitar a diversidade dos diferentes locais e regiões é articulá-los no todo, e não isolá-los. Isso porque o isolamento tende a fazer degenerar a diversidade em desigualdade, cristalizando-a pela manutenção das deficiências 
locais. Inversamente, articuladas no sistema, enseja-se a possibilidade de fazer reverter as deficiências, o que resultará no fortalecimento das diversidades em benefício de todo o sistema. (Idem, ibid., p. 5)

Cabe, portanto, à União (art. $8^{\circ}, \S 1^{\circ}$ da LDB) a articulação da política nacional de educação e, consequentemente, da educação profissional e tecnológica, pondo em reciprocidade os diversos níveis e sistemas de ensino e usando para isso suas funções de normatizar, redistribuir e suplementar.

O inciso XXIV do artigo 22 da Constituição Federal determina que é competência privativa da União legislar diretrizes e bases da educação nacional. Em setembro de 2012, foram aprovadas novas diretrizes curriculares nacionais para a educação profissional técnica de nível médio. No parágrafo único do artigo $1^{\circ}$ da Resolução CNE/CEB n. 6/12, que as aprovou, consta que diretriz refere-se ao "[...] conjunto articulado de princípios e critérios a serem observados pelos sistemas de ensino e pelas instituições de ensino públicas e privadas [...]". (BRASIL, 2012). Além dessas diretrizes nacionais e específicas para a educação profissional técnica de nível médio, os sistemas e instituições de ensino devem observar as diretrizes curriculares nacionais gerais para a educação básica (Resolução CNE/CEB n. 4/10) e diretrizes curriculares nacionais para o ensino médio (Resolução CNE/CEB n. 2/12).

O Ministério da Educação (MEC) tem, na Setec, a instância que exerce suas funções de planejamento, orientação, coordenação e supervisão nessa área. Ela o faz por meio de três diretorias: a de Políticas de Educação Profissional e Tecnológica; a de Integração das Redes de Educação Profissional e Tecnológica e a de Desenvolvimento da Rede Federal de Educação Profissional e Tecnológica.

Esta última tem a tarefa de por em ação o papel da União de também executar a oferta dessa modalidade educacional. A Lei n. 11.892/08, ao criar os institutos federais, estabeleceu que cada um, entre outros desafios, deve responder pela sua qualificação como "[...] centro de referência no apoio à oferta do ensino de ciências nas instituições públicas de ensino, oferecendo capacitação técnica e atualização pedagógica aos docentes das redes públicas de ensino". Constitui-se também como um dos seus objetivos a oferta de "cursos de licenciatura, bem como programas especiais de formação pedagógica, com vistas à formação de professores para a educação básica, sobretudo nas áreas de ciências e matemática, e para a educação profissional". (BRASIL, 2008).

A essas instituições educacionais foi conferido o papel de apoiar a estruturação do desenvolvimento de territórios. Para tanto, devem participar de articulações intergovernamentais e concorrer para que os entes envolvidos incorporem ao diálogo, do qual participam as comunidades, entidades e associações da sociedade civil e o sistema produtivo, visando à construção de projetos territoriais de educação, 
trabalho e cidadania. Com variados graus de desenvolvimento e resultados, há diversas iniciativas em andamento nos institutos federais que buscam cooperar com as redes estaduais e municipais de ensino na oferta de licenciaturas, de formação inicial e continuada, cursos técnicos presenciais e a distância, incluindo cursos médios integrados regulares e na modalidade de educação de jovens e adultos. As instituições da Rede Federal de Educação Profissional, Científica e Tecnológica recebem, para tanto, recursos específicos da Setec e os diretos do Tesouro Nacional.

Quanto à Diretoria de Políticas de Educação Profissional e Tecnológica da Setec, entre outras de suas funções, está a de promover a atualização do Catálogo Nacional de Cursos Técnicos (CNCT), um importante instrumento de gestão que oferece parâmetros aos entes federados para a expansão da educação profissional e tecnológica. O CNCT faz parte do processo de regulação educacional realizado pelo MEC com o objetivo de estabelecer referenciais e metodologias de acompanhamento e avaliação de cursos e instituições, no que se refere a condições de funcionamento, resultados e caráter ordenado da oferta. Ele regulamenta as denominações dos cursos, define perfis profissionais, estabelece alguns requisitos, contribuindo para a formulação, desenvolvimento e avaliação de projetos pedagógicos. Contribui, ainda, para afirmar o caráter e a validade nacional dos diplomas.

O primeiro CNCT surgiu em 2008 e resultou de um processo participativo, no qual se integraram especialistas, pesquisadores, instituições de ensino e entidades de representação. Passou por consulta pública, tendo em vista colher sugestões de correções e aperfeiçoamentos. Havia, no país, uma profusão de denominações de cursos técnicos, muitas totalmente descabidas por trazer recortes hiper-especializados, redundâncias com relação a ofertas existentes, conflitos com atribuições privativas de profissões regulamentadas, apelos especificamente mercadológicos, entre outros. Percebeu-se que parte do problema derivava do uso de lógicas diferentes para a classificação dos cursos, o que levou a Setec a estabelecer um único critério, considerando o eixo tecnológico de definição do domínio do curso. O CNCT vem contribuindo, assim, para organizar a oferta dos cursos técnicos; construir o mapa da educação profissional e tecnológica brasileira; ajudar na definição dos investimentos; aumentar a confiabilidade dos cursos e estabelecer referenciais de qualidade. Trata-se de um instrumento de gestão dinâmico, pois sofre atualizações periódicas para as quais setores diversos das redes federal, do Distrito Federal, dos estados e municípios têm contribuído. A Comissão Executiva Nacional do Catálogo Nacional de Cursos Técnicos (Conac) subsidia a Setec nesse processo e se compõe de representantes dos conselhos estaduais, do Conselho Nacional de Educação (CNE), de especialistas da área de educação profissional e tecnológica, além de técnicos do próprio MEC, num processo singular de cooperação federativa. 
Outro instrumento de cooperação federativa é o Fundo de Manutenção e Desenvolvimento da Educação Básica e de Valorização dos Profissionais da Educação (Fundeb). Previsto para vigorar entre 2007 e 2020, de natureza contábil, é formado por recursos originados das três esferas de governo (federal, estadual e municipal), não se configura como entidade jurídica, mas como um tipo de gestão administrativa e financeira de recursos realizada por meio de articulação intergovernamental. Destina-se ao financiamento da educação básica pública em todas as suas modalidades, inclusive a educação profissional e a educação de jovens e adultos, ofertas não contempladas pelo fundo que o antecedeu, o Fundef, que esteve em vigor entre 1998 e 2006 e era restrito ao ensino fundamental. No documento "Fundo de Manutenção e Desenvolvimento da Educação Básica e de Valorização dos Profissionais da Educação - Fundeb - Perguntas Frequentes", de 2009, o MEC informa que:

Assim, dependendo da ótica que se observa, o Fundo tem seu vínculo com a esfera Federal (a União participa da composição e distribuição dos recursos), a Estadual (os estados participam da composição, da distribuição, do recebimento e da aplicação final dos recursos) e a Municipal (os municípios participam da composição, do recebimento e da aplicação final dos recursos). (BRASIL, 2009, p. 4)

Segundo o mesmo documento, ficou definido que, a partir de 2010, a complementação da União passaria a ser de 10\% do valor total do Fundo (idem, ibid.).

O artigo 10 da lei que o regulamentou (Lei n. 11.494/07) esclarece quais etapas, modalidades e tipos de estabelecimento de ensino da educação básica podem se beneficiar dos recursos desse Fundo, entre eles o ensino médio integrado à educação profissional (inciso XIII) e a educação de jovens e adultos integrada à educação profissional de nível médio, com avaliação no processo (XVII). ${ }^{1}$

Para especificar anualmente as ponderações aplicáveis à distribuição proporcional dos recursos, inclusive para a destinação da educação profissional, o artigo 12 dessa Lei instituiu, no âmbito do MEC, a Comissão Intergovernamental de Financiamento para a Educação Básica de Qualidade. Sua composição expressa o sentido da cooperação federativa, pois se faz por:

I - 1 (um) representante do Ministério da Educação;

II - 1 (um) representante dos secretários estaduais de educação de cada uma das 5 (cinco) regiões político-administrativas do Brasil indicado pelas seções regionais do Conselho Nacional de Secretários de Estado da Educação - Consed;

III - 1 (um) representante dos secretários municipais de educação de cada uma das 5 (cinco) regiões político-administrativas do Brasil indicado pelas seções regionais da União Nacional dos Dirigentes Municipais de Educação - Undime. (BRASIL, 2007) 
Vinculado ao MEC, também o Instituto Nacional de Estudos e Pesquisas Educacionais Anísio Teixeira (Inep) constitui-se num suporte estruturante do processo de cooperação federativa, ao promover estudos, pesquisas e avaliações de interesse dos sistemas de ensino e para a formulação e implementação de políticas públicas para a área da educação, com base em parâmetros de qualidade. Com finalidade semelhante, o MEC criou o Sistema Nacional de Informações da Educação Profissional e Tecnológica (Sistec), que disponibiliza informações diversas sobre cursos técnicos de nível médio e de formação inicial e continuada das redes de ensino, vagas georreferenciadas, suporte à gestão e controle das ações.

\section{Colaboração federativa na educação profissional e tecnológica brasileira}

A colaboração federativa depende da vontade política dos entes federados de compartilhar as propostas de políticas educacionais. Ela promove arranjos educativos e de gestão de políticas públicas baseados em vínculos e redes de interdependência, articulação e solidariedade, que se expressam por convênios, acordos e termos de adesão. Algumas das políticas de colaboração no campo da educação profissional e tecnológica são as seguintes:

\section{Programa Nacional de Integração da Educação Profissional com a Educação Básica na Modalidade de Educação de Jovens e Adultos (Proeja)}

Com a criação desse Programa, as redes de ensino (federal, estaduais e municipais) foram convocadas a reforçar suas parcerias diante da urgente necessidade de conferir oportunidades a milhões de jovens e adultos brasileiros com 15 anos e mais, sem escolaridade ou com escolaridade inferior ao ensino fundamental completo. O governo federal instituiu o Proeja inicialmente apenas no âmbito da rede federal (Decreto n. 5.478/05). No ano seguinte, por meio do Decreto n. 5.840/06, incorporou a possibilidade de sua oferta por instituições públicas dos sistemas de ensino estaduais e municipais, mas estabeleceu que "[...] cursos e programas do Proeja deverão ser oferecidos, em qualquer caso, a partir da construção prévia de projeto pedagógico integrado único, inclusive quando envolver articulações interinstitucionais ou intergovernamentais" (BRASIL, 2006). Isso significou um novo desafio para os órgãos estaduais responsáveis pela educação profissional e tecnológica, especialmente para os que não pertencem às secretarias estaduais de Educação ou que dividem suas responsabilidades com outros órgãos da administração pública e/ou com organizações sociais com as quais são estabelecidos contratos de gestão. Ou seja, conteúdos de educação geral (ensino fundamental e 
médio) e de educação profissional (formação inicial e continuada e cursos técnicos) devem fazer parte de um projeto pedagógico integrado único, independentemente se a oferta for de forma integrada, subsequente ou concomitante. Com tal exigência, o Decreto n. 5.840/06 compele as redes estaduais e municipais de ensino a articulações intergovernamentais, um importante pressuposto para o processo de colaboração federativa. No caso dos municípios que não possuem escolas que ministrem cursos de educação profissional, tais articulações podem se realizar por meio de acordos com outras redes (federal, distrital, estaduais e outras de âmbito municipal). O papel da União, por meio do MEC, é de participar dessas articulações por meio da rede federal de educação profissional, científica e tecnológica, da assistência técnica, do fomento à formação de profissionais para a atuação nesse Programa, da promoção de pesquisas sobre o tema, de monitoramentos e avaliações e de diversas outras formas de estímulo às articulações dos entes federados. $\mathrm{O}$ enraizamento dessa política, por meio da concretização do conjunto dessas ações colaborativas envolvendo todos os entes federados, constitui a medida do efetivo entendimento do que a Constituição Federal determina no seu artigo 208 e do que a LDB, no seu artigo 37, § 3으, preconiza: a articulação preferencial da educação de jovens e adultos com a educação profissional.

\section{Programa Brasil Profissionalizado}

Criado pelo Decreto n. 6.302/07, esse Programa se constitui como forma de colaboração federativa por meio da qual a União busca induzir e fomentar a expansão da oferta de educação profissional e tecnológica pelos estados, Distrito Federal e municípios. Inicialmente, essa indução visou à oferta do modelo de ensino médio integrado à educação profissional, mas no ano seguinte, 2008, incluiu as formas subsequente e concomitante ao ensino médio. Para ter suas propostas analisadas pelo Brasil Profissionalizado, estados, Distrito Federal e municípios devem aderir formalmente ao Plano de Metas Compromisso Todos pela Educação, nos termos do Decreto n. 6.094/07, obrigando-se a cumprir 28 metas de melhoria da qualidade da educação básica. Pressupõe-se que a colaboração entre entes federados inclua a participação de famílias e comunidades. Como modalidade da educação básica, a educação profissional e tecnológica se valoriza com o cumprimento de tais metas, pois estas buscam a efetividade de aprendizagens, a redução de repetências e evasões, inclusão educacional, valorização dos profissionais da educação, gestão participativa e transparente, articulação com políticas públicas, com a comunidade e associações da sociedade civil. $\mathrm{O}$ apoio do MEC para a realização de tais metas contempla eixos do plano plurianual da União: a gestão educacional; a formação de professores e profissionais de serviços e apoio escolar; os recursos pedagógicos; a infraestrutura física. A adesão 
a essa colaboração pressupõe a realização de diagnósticos e, com base neles, a elaboração de um Plano de Ações Articuladas (PAR), para os quais o MEC disponibiliza aos entes federados assistência técnica e um sistema (Simec-Módulo PAR Plano de Metas), conectado à internet, instrumento que também serve ao acompanhamento público e ao controle social. Cabe ao MEC coordenar a implantação, o acompanhamento, o monitoramento, a supervisão e a avaliação desse Programa. Por meio de convênios, os entes subnacionais recebem recursos para financiar a construção, ampliação, modernização e adequação de espaços físicos destinados à educação profissional; laboratórios de física, química, biologia, informática e os recomendados pelo Catálogo Nacional de Cursos Técnicos; acervos bibliográficos; materiais de consumo. As aquisições de equipamentos para laboratórios e salas de educação a distância, bem como os investimentos em infraestrutura pressupõem a observação por parte dos entes federados de parâmetros estabelecidos pelo MEC. Quanto às ações de formação de docentes, gestores e pessoal técnico-administrativo das redes conveniadas, a preferência desse Ministério é de que sejam realizadas por instituições federais de educação.

\section{Sistema Escola Técnica Aberta do Brasil - e-Tec Brasil e Rede e-Tec Brasil}

Também em 2007 foi instituído o Sistema Escola Técnica Aberta do Brasil e-Tec Brasil (Decreto n. 6.301/07), destinado à interiorização, democratização e desenvolvimento da educação profissional técnica por meio de cursos a distância, públicos e gratuitos. Esse Programa propôs a criação de uma rede nacional de educação profissional nas instituições públicas de ensino, para a oferta de cursos a distância em escolas públicas municipais e estaduais, e está pautado na colaboração federativa. Em 2011, instituiu-se a Rede e-Tec Brasil pelo Decreto n. 7.589/11. A ela podem aderir instituições da rede federal e instituições de educação profissional vinculadas aos sistemas estaduais de ensino. Podem aderir também as unidades de ensino dos serviços nacionais de aprendizagem que ofertam cursos de educação profissional e tecnológica. Cabe a tais instituições e unidades de ensino a constituição de polos de apoio presencial para a execução de atividades didático-administrativas de suporte aos cursos ofertados, os quais devem ser instalados preferencialmente em escolas públicas municipais, estaduais e do Distrito Federal. Poderão ser instalados também em instituições públicas que ofertem cursos de educação profissional e tecnológica e em unidades de ensino dos serviços nacionais de aprendizagem. Cabe ao MEC fixar critérios de habilitação desses polos, coordenar a implantação, acompanhar, supervisionar e avaliar as atividades dessa Rede, apoiar financeiramente, prestar suportes técnicos, entre eles a oferta - por meio de instituições federais de ensino - de cursos de especialização em gestão e docência em educação a distância para profissionais que atuam nessa Rede. 


\section{Programa Nacional de Acesso ao Ensino Técnico e Emprego (Pronatec)}

O ano de 2011 trouxe também o Pronatec, a partir da Lei n. 12.513/11, mais uma iniciativa da União para ampliar a oferta de educação profissional e tecnológica no país, por meio de assistência técnica e financeira, cobrindo cursos técnicos presenciais e a distância e os de formação inicial e continuada. Em 2013, por meio de redação dada pela Lei n. 12.816, no regime de colaboração destinado ao Pronatec, foi incluída a adesão voluntária dos serviços nacionais de aprendizagem, de instituições privadas e públicas de ensino superior, de instituições de educação profissional e tecnológica e de fundações públicas de direito privado, precipuamente dedicadas à educação profissional e tecnológica. Ele traz novos instrumentos de financiamento pela União. O primeiro, a bolsa-formação apresentada em duas modalidades: bolsaformação estudante e bolsa-formação trabalhador, esta combinada com as políticas do Seguro-Desemprego ou com a de Inclusão Produtiva. O segundo, o Fies Técnico, uma linha de crédito para facilitar o acesso de estudantes e trabalhadores empregados ao ensino técnico, também em duas modalidades: Fies Técnico - Estudante e Fies Técnico - Empresa. Para tanto, articula-se com o Sistema Nacional de Emprego e com o Programa Nacional de Inclusão de Jovens (Projovem). Os recursos financeiros correspondentes aos valores das bolsas-formação são transferidos às instituições e dispensa-se a realização de convênio, acordo, contrato, ajuste ou instrumento congênere, bastando a assinatura de termo de adesão e o cumprimento de normas obrigatórias, entre elas a de prestação de contas da aplicação dos recursos.

\section{Programa Nacional Mulheres Mil}

Instituído pela Portaria n. 1.015, de 21 de julho de 2011, visa à formação profissional e tecnológica articulada com elevação de escolaridade de mulheres em situação de vulnerabilidade social, constituindo-se como uma das ações do Plano Brasil Sem Miséria. Prioritariamente, deve ser ofertado pelas instituições públicas dos sistemas de ensino dos entes federados. Os cursos de formação inicial e continuada de trabalhadores e de educação profissional técnica de nível médio devem estar articulados ao ensino fundamental ou ao médio. Também incorporam o processo de reconhecimento de saberes e de certificação no âmbito da Rede Certific do MEC.

\section{Participação do setor privado nos arranjos da colaboração federativa para oferta da educação profissional e tecnológica}

A União, o Distrito Federal, os estados e os municípios vêm - cada um na sua esfera de atuação e nível de responsabilidade - sendo desafiados a investir nas suas capacidades institucionais de atendimento às crescentes e novas demandas sociais 
por educação profissional e tecnológica, que requerem não somente a expansão de vagas, como também a diversificação de cursos. São pressões decorrentes de exigências da economia e do aumento da complexidade da vida em sociedade, que têm se traduzido por expectativas de formação profissional correspondentes aos padrões de inovação tecnológica e organizacional próprios da atual dinâmica de reestruturação dos processos produtivos e de mundialização cultural e econômica. Em contrapartida, os governos, nos diferentes níveis da organização federativa brasileira, têm também experimentado pressões para reduzir os custos do estado, o que os tem levado à adoção de princípios de gestão e de financiamento inspirados na lógica empresarial gerencialista: maximização de resultados com o menor dispêndio de investimentos.

Para dar conta da relação entre tais variáveis, seus graus de variação, funções e reações e na falta de um regime de cooperação federativa mediante o qual fossem definidas atribuições institucionais, regras e procedimentos claros de relações intergovernamentais, a União vem assumindo o papel de indutora do desenvolvimento da educação profissional e tecnológica no país. Paralelamente, em todos os níveis da Federação, os governos têm experimentado estratégias de administração pública referenciadas na lógica gerencialista e de incentivos públicos a setores da sociedade civil (empresas privadas e segmentos paraestatais, principalmente) para participar da elaboração, implementação e acompanhamento das políticas públicas educacionais. Entre os estímulos, estão os repasses de recursos públicos, financiamentos mediados por termos de parcerias, convênios e contratos de gestão.

São inúmeros os casos que poderiam ser citados como exemplos desses artifícios utilizados para viabilizar a oferta de educação profissional e tecnológica, mediante transferência de recursos públicos para o setor privado. O convênio firmado em julho de 2012 pela Secretaria Estadual de Educação do Paraná com o Instituto Walmart, vinculado à rede norte-americana multinacional de supermercados, para a formação profissional de estudantes como padeiros, açougueiros, peixeiros e confeiteiros, atendendo aos interesses dessa empresa, motivou protestos do movimento estudantil nacional e do estado: "Nós estudantes não somos mão de obra barata para sermos comercializados em convênios governamentais, apenas por interesses individuais e políticos". ${ }^{2} \mathrm{O}$ sindicato dos professores do estado paranaense também repudiou essa parceria público-privada, vendo-a como estratégia de terceirização das atividades de ensino que põe de lado "os esforços para a construção de uma educação profissional pública de qualidade para nossos jovens". ${ }^{3}$ No Rio de Janeiro, esse tipo de parceria ou terceirização também tem ocorrido, envolvendo diversas escolas públicas estaduais e diferentes empresas privadas, tais como as estabelecidas entre o Instituto Oi Futuro e o Colégio Estadual José Leite Lopes; entre o Grupo Pão de Açúcar e o Colégio Estadual Comendador Valentim dos Santos Diniz; entre a empresa Thyssenkrupp 
CSA e o Colégio Estadual Erich Walter Heine. ${ }^{4}$ Em São Paulo, o Centro Paula Souza, autarquia estadual que administra as escolas técnicas e faculdades de tecnologia do estado, transferiu, mediante convênio, a gestão administrativa e financeira dos cursos de pós-graduação dessas faculdades para a Fundação de Apoio à Tecnologia (FAT), entidade de direito privado. ${ }^{5}$ Tais exemplos não são casos isolados, mas uma prática que vem se tornando muito comum nas redes públicas de ensino do país.

Silva e Dore (2011, p. 77) relatam a estratégia de compra de vagas na rede privada praticada pelo Programa de Educação Profissional (PEP), do governo do estado de Minas Gerais, criado em 2007: "primeiramente, o governo extinguiu a formação profissional nas escolas de nível médio do estado, em 1996, e, dez anos depois, por meio da política do PEP, passou a comprar vagas na rede privada para oferecê-las aos estudantes que desejam uma formação técnico-profissional". Antecedendo a cisão entre educação geral e educação profissional no ensino médio, que veio a ser consagrada pelo Decreto n. 2.208/97, o governo mineiro a materializou ao implementar, sob a orientação do Banco Mundial, o Programa de Melhoria do Ensino Médio, no contexto do Projeto de Melhoria da Qualidade na Educação Básica, financiado mediante empréstimo obtido, em 1995, junto a esse banco. Os autores constataram que o PEP tem sofrido o peso de uma alta e surpreendente evasão escolar: "mesmo que os alunos disponham dos recursos oferecidos pelo governo para realizar sua formação profissional, é elevada a quantidade daqueles que abandonam os cursos profissionalizantes" (SILVA; DORE, 2011, p. 84). Ou seja, a opção de Minas Gerais de comprar vagas na rede privada, de privilegiar a mercantilização da educação profissional e tecnológica e de fomentar o crescimento do setor educacional privado também pode ser vista como estratégia que desperdiça recursos públicos e de baixa eficiência, ao responder problemas que pressupõem políticas orientadas por critérios de qualidade social.

Quanto ao Pronatec, a lei que o criou previa sua execução por meio de programas, projetos e ações de assistência técnica e financeira em regime de colaboração com os estados, Distrito Federal e municípios, mas também mediante a participação dos serviços nacionais de aprendizagem, entidades paraestatais já subsidiadas por contribuições instituídas pela União que incidem sobre a folha de salários. Em 2013, o Pronatec, ao receber novas regulamentações (Lei n. 12.816), passou a incluir a participação nesse programa de instituições privadas e públicas de ensino superior, de instituições de educação profissional e tecnológica e de fundações públicas de direito privado, desde que precipuamente dedicadas à educação profissional e tecnológica. Os dois tipos de bolsas por ele concedidas (bolsa-formação estudante e bolsa-formação trabalhador) são transferência de valores às instituições privadas que ofertam os cursos. Além disso, pela modalidade Fies-Empresa, empresas podem tomar empréstimo para financiar cursos de formação inicial e continuada e 
de educação profissional técnica de nível médio exclusivamente de seus interesses. Outro aspecto a considerar é que, pelo Pronatec, também se faz pagamento de bolsas a professores de instituições de educação profissional das redes públicas que nele atuam, uma remuneração que se superpõe à recebida por esses servidores públicos contratados para exercerem funções educacionais de mesma finalidade.

Tais expedientes de transferência de recursos públicos para setores privados encontram justificativas na fragilidade estrutural das redes públicas de ofertar a educação profissional e tecnológica que o país carece. São situações criadas pelo descaso histórico com essa modalidade educacional por parte do poder público, mas que foram reforçadas pela reforma administrativa do Estado brasileiro dos anos de 1990, que apregoou a redução do tamanho do Estado. A parceria público-privada foi, então, instituída juridicamente para dar sustentação a essa reforma administrativa, encontrando na Emenda Constitucional n. 19/98 o marco decisivo dessa virada conceitual e política. Essa emenda forneceu referências para normas jurídicas sobre o estabelecimento de parcerias entre a administração pública, inclusive as agências executivas ou entidades públicas estatais, o setor privado e as paraestatais ou o chamado Terceiro Setor.

As entidades paraestatais incluem o conjunto de entidades paralelas ao Estado, incluem os serviços sociais autônomos (Sesi, Sesc, Senai, Sebrae), as entidades de apoio (fundações, associações e cooperativas), as organizações sociais (OS) e as organizações da sociedade civil de interesse público (Oscip). (ADRIÃO; BEZERRA, 2013, p. 259)

Complementarmente, a Lei Federal n. 11.079/04 instituiu normas gerais para licitação e contratação de parceria público-privada no âmbito da administração pública. Na esfera educacional, o Decreto n. 6.094/07, ao instituir o Plano de Metas Compromisso Todos pela Educação, estabeleceu a adesão voluntária de compromisso a 28 diretrizes políticas como forma e critério para o estabelecimento das parcerias entre União, Distrito Federal, estados e municípios e setor privado para ações no campo da educação.

A participação do setor privado nos arranjos da colaboração federativa apresenta algumas implicações importantes para o desenvolvimento da educação profissional e tecnológica no país.

Em primeiro lugar, espaços públicos são apropriados pelo setor privado ou passam a ser geridos conforme critérios gerenciais de empresas. Além disso, aumenta-se a ingerência empresarial em currículos e práticas pedagógicas. Em todos os casos, há o fortalecimento do mercado privado de oferta da educação profissional e tecnológica.

Em segundo lugar, o Estado, ao se desobrigar de cumprir suas responsabilidades educacionais e ao colocá-las a cargo do setor privado ou paraestatal, retira a 
oferta educacional da esfera democrática e desestimula a estruturação das redes públicas de educação profissional e tecnológica, reproduzindo mecanismos que o torna cada vez mais dependente da oferta proveniente da rede privada.

Por fim, tal transferência de responsabilidades e recursos induz à crença infundada de que, necessariamente, a educação de qualidade é sempre a ministrada pela esfera privada, esquecendo-se de que há financiamentos públicos de ações privadas cujas metas nem sempre são cumpridas, que tais ações são realizadas, em muitos casos, mediante a precarização dos trabalhadores envolvidos na sua execução ou mesmo dos serviços prestados. No caso destes últimos, perspectivas curriculares fragmentadas e a oferta de educação profissional técnica de nível médio, concomitante ao ensino médio, podem ganhar a preferência. Assim, no uso do Fies-Empresa, as empresas "podem optar preferencialmente ou exclusivamente por cursos técnicos não integrados ou formas de qualificação mais rápidas e focadas nos seus processos produtivos, jogando o papel mediador da educação no pragmatismo do imediatismo" (LIMA, 1912, p. 83).

\section{Considerações finais}

A II Conae está sendo organizada para ser um espaço democrático de construção de consensos, tendo em vista "renovadas perspectivas para a organização da educação nacional e a consolidação do novo PNE" (BRASIL, 2012, p. 8). Ainda em discussão no Congresso Nacional, o PNE 2011-2020 (Projeto de Lei n. 8.035/10), entretanto, dá continuidade à lógica da cooperação, em conformidade com o artigo 214 da Constituição Federal.

Não há dúvida de que os arranjos de cooperação entre entes federados podem resultar em valiosas aprendizagens, aproveitamentos de potenciais e oportunidades, aumentos de capacidades de atendimento à população, inovações, fomentos de investimentos em áreas complementares, impactos na fronteira tecnológica, redistribuição da riqueza cultural, minimização das desigualdades sociais, desenvolvimentos educacionais e locais. Contudo, precisam contar com consensos, ter consistência e regularidade nos padrões de interação e reciprocidade entre os entes participantes, e isso não tem ocorrido em alguns casos, pois são políticas de governos e não de Estado. Consequentemente, a estruturação da educação profissional nas redes de ensino subnacionais nem sempre é possibilitada pelo regime de colaboração. Concorrem, ainda, para isso, as estratégias de parcerias público-privadas.

As ações do governo federal no campo das políticas de educação profissional e tecnológica apresentam, nos últimos anos, saldos positivos em muitos sentidos, pois estão levando à ampliação, reestruturação e interiorização da rede federal e ao 
alargamento e melhoria de infraestrutura e qualificação de recursos pedagógicos de algumas redes estaduais. Com isso, essas redes tiveram suas capacidades de oferta aumentadas, permitindo elevar o atendimento à população de um número maior de municípios. O Sistema de Seleção Unificada do Ensino Técnico e Profissional (Sisutec), que utiliza resultados do Exame Nacional do Ensino Médio (Enem), surgiu como um mecanismo para viabilizar um melhor aproveitamento das vagas decorrentes da política de expansão dessa modalidade de educação.

Entretanto, ainda permanecem grandes desigualdades regionais quanto ao acesso e permanência. A evasão nos cursos técnicos e de formação inicial e continuada é reveladora da necessidade urgente de estabelecimento de referenciais de qualidade e de dotar caráter estruturante a tais ações ainda muito fragmentadas. Particularmente, na esfera subnacional, é preciso maior consideração com a valorização dos profissionais que atuam nesse segmento educacional, para os quais não há políticas de formação e carreira e as condições de trabalho deixam muito a desejar.

A questão do financiamento denuncia a grande vulnerabilidade da estratégia baseada em regime de colaboração: os entes subnacionais, em sua grande maioria, são muito dependentes dos recursos advindos dos programas governamentais, falta política de financiamento estável, há casos de irregularidades que minam os investimentos em educação, repasses para instituições privadas que nem sempre permitem um efetivo controle social.

Por tudo isso, faz sentido esperar que a II Conae traga de fato renovadas perspectivas para a organização da educação profissional e tecnológica. É preciso comprometer os entes federados com a estruturação dessa modalidade educacional em suas redes, contemplá-la em alguma medida na Lei de Responsabilidade Educacional, regulamentar o regime de cooperação institucional. Estas são premissas fundamentais para a construção de um Sistema Nacional de Educação, que faça jus ao princípio do dever do Estado de atender ao direito humano fundamental à educação, inclusive à educação profissional e tecnológica.

\section{Notas}

1. Além da educação profissional pública, recursos do Fundeb, por meio da articulação federativa da União com alguns governos estaduais, também estão sendo aplicados para financiar as 135 Escolas Família Agrícola (EFAs) existentes no país, na sua oferta de ensino médio integrado a cerca de 15 mil jovens de famílias de pequenos agricultores. Disponível em: <https://conteudoclippingmp. planejamento.gov.br/cadastros/noticias/2013/6/13/fundeb-vai-financiar-escolas-familia-agricola>. Acesso em: 20 set. 2013.

2. Disponível em: <http://www.une.org.br/2012/08/pr-estudantes-repudiam-convenio-do-estado-como-walmart/>. Acesso em: 15 nov. 2013.

3. Disponível em: <http://www.appsindicato.org.br/Include/Paginas/noticia.aspx?id=7497>. Acesso em: 15 nov. 2013. 
4. Disponível em: <http://www.rj.gov.br/web/seeduc/exibeconteudo?article-id=1171009>. Acesso em: 14 nov. 2013.

5. Disponível em: <http://www.fundacaofat.org.br/cursos/>. Acesso em: 15 nov. 2013.

\section{Referências}

ADRIÃO, T.; BEZERRA, E.P. O setor não lucrativo na gestão da educação pública: corresponsabilidade ou debilidade. Currículo sem Fronteiras, v. 13, n. 2, p. 256-268, maio/ ago. 2013. Disponível em: <http://www.curriculosemfronteiras.org/vol13iss2articles/ adriao-bezerra.pdf>

BATISTOLLI, E.C.; GROSSI JR., G.; GARCIA, S.R. As redes estaduais de ensino e a construção de uma política nacional de educação profissional. In: MOLL, J. et al. Educação profissional e tecnológica no Brasil contemporâneo: desafios, tensões e possibilidades. Porto Alegre: Artmed, 2010. p. 195-206.

BRASIL. Decreto n. 5.840, de 13 de julho de 2006. Institui, no âmbito federal, o Programa Nacional de Integração da Educação Profissional com a Educação Básica na Modalidade de Educação de Jovens e Adultos - Proeja, e dá outras providências. Brasília, DF, 2006.

BRASIL. Lei n. 11.494, de 20 de junho de 2007. Regulamenta o Fundo de Manutenção e Desenvolvimento da Educação Básica e de Valorização dos Profissionais da Educação - Fundeb, de que trata o art. 60 do Ato das Disposições Constitucionais Transitórias; altera a Lei n. 10.195, de 14 de fevereiro de 2001; revoga dispositivos das Leis n. 9.424, de 24 de dezembro de 1996, 10.880, de 9 de junho de 2004, e 10.845, de 5 de março de 2004; e dá outras providências. Brasília, DF, 2007.

BRASIL. Lei n. 11.892, de 29 de dezembro de 2008. Institui a Rede Federal de Educação Profissional, Científica e Tecnológica, cria os Institutos Federais de Educação, Ciência e Tecnologia, e dá outras providências. Brasília, DF, 2008.

BRASIL. MEC. Fundo de Manutenção e Desenvolvimento da Educação Básica e de Valorização dos Profissionais da Educação Fundeb - Perguntas Frequentes. Brasília, DF, 2009. 52p.

BRASIL. MEC. O PNE na articulação do sistema nacional de educação: participação popular, cooperação federativa e regime de colaboração. Documento-referência da Conae 2014. Brasília, DF: MEC, 2012.

BRASIL. MEC. CNE. CEB. Resolução n. 6, de 20 de setembro de 2012. Define Diretrizes Curriculares Nacionais para a Educação Profissional Técnica de Nível Médio. Diário Oficial da União, Brasília, DF, Seção 1, p. 22, 21 set. 2012. 
DIEESE. Modelos de gestão e perfil da oferta de educação profissional nas redes estaduais. Salvador, BA, 2012. 51p.

FÓRUM NACIONAL DE EDUCAÇÃO. Conae 2014. Regimento Interno. Brasília, DF, 2012.

FÓRUM NACIONAL DE GESTORES ESTADUAIS DE EDUCAÇÃO PROFISSIONAL. Regimento Interno. Brasília, DF, 2005. (mimeo.).

LIMA, M. Problemas da educação profissional do governo Dilma: Pronatec, PNE e DCNEMs. Trabalho E Educação, Belo Horizonte, v. 21, n. 2, p. 73-91, maio/ago. 2012.

SAVIANI, D. Plano Nacional de Educação, a questão federativa e os municípios: o regime de colaboração e as perspectivas da educação brasileira. Conferência proferida na Seção de Abertura do 60 ${ }^{0}$ Fórum Internacional de Educação da Região Metropolitana de Campinas e 1ํo Fórum de Educação de Paulínia em 29 de agosto de 2011. Disponível em: <http://www.6forumrmc.org.br/files/programacao/Dermeval_Saviani. pdf>. Acesso em: 21 set. 2013.

SOUZA, D.B.; RAMOS, M.N.; DELUIZ, N. Cobertura municipal da educação profissional via regime de colaboração: uma prática possível? Ensaio: aval. pol. públ. educ., Rio de Janeiro, v. 15, n. 54, p. 29-52, jan./mar. 2007.

SILVA, W.A.; DORE, R. O Programa de Educação Profissional de Minas Gerais e a evasão escolar: um estudo preliminar (2008-2010). Educação em foco, Belo Horizonte, ano 14, n. 18, p. 75-95, dez. 2011.

Recebido em 4 de outubro de 2013.

Aprovado em 21 de novembro de 2013

Educ. Soc., Campinas, v. 34, n. 125, p. 1113-1133, out.-dez. 2013 
